\title{
Molecular mechanisms of apoptosis in the liver of rats after portal branch ligation with and without retrorsine
}

\author{
Christian Picard ${ }^{1}$, Peter Starkel ${ }^{1}$, Christine Sempoux ${ }^{2}$, Alain Saliez ${ }^{3}$, Valérie Lebrun ${ }^{1}$ \\ and Yves Horsmans ${ }^{1}$ \\ ${ }^{1}$ Laboratory of Gastroenterology; ${ }^{2}$ Laboratory of Pathology and ${ }^{3}$ Laboratory of Experimental Surgery, \\ University of Louvain Medical School, Brussels, Belgium
}

\begin{abstract}
The mechanisms accounting for the atrophy of the portal blood-deprived liver lobes after portal branch ligation (PBL) are still unclear. The first aim of this study was to confirm the role of apoptosis in this process and to determine which apoptotic pathways are involved. The second aim of the study was to evaluate the effect of blocking compensatory hyperplasia of the nonligated lobes with retrorsine on the mechanisms of apoptosis in the ligated lobes. Mitochondrial Bax, Bcl-2 and $\mathrm{Bcl}-\mathrm{X}_{\mathrm{L}}$, cytosolic cytochrome $c$, caspase-3, -8 and -9 activities and TNF- $\alpha$ levels were assessed in the liver of rats before and at various time points, ranging from $30 \mathrm{~min}$ to 7 days, after PBL. Caspase activities were also measured in rats pretreated with retrorsine. Both the mitochondrial and the death receptor-mediated pathways are activated in the ligated liver lobes after portal branch ligation. Caspase activation is inhibited by retrorsine pretreatment, resulting in fewer apoptotic bodies. Apoptosis accounts for the atrophy of the ligated lobes after PBL. It is inhibited by retrorsine, suggesting an attempt to reduce the loss of liver mass when hyperplasia of the nonligated lobes is impaired.

Laboratory Investigation (2004) 84, 618-628, advance online publication 29 March 2004; doi:10.1038/labinvest. 3700085
\end{abstract}

Keywords: portal branch ligation; liver regeneration; apoptosis; caspase; Bcl-2; retrorsine

After ligation of branches of the portal vein (portal branch ligation, PBL), interrupting portal blood inflow to the left lateral and medial lobes, the portal blood deprived lobes undergo atrophy, while the nonligated lobes proliferate, compensating for the loss of liver mass. This model was first described in rats in $1920{ }^{1}$ Liver regeneration of the proliferating lobes after PBL has been extensively studied and has been shown to be similar to that observed after partial hepatectomy. ${ }^{2-4}$

In contrast, the precise events resulting in the atrophy of the ligated lobes have not been described yet. This is rather surprising, as apoptosis, first called shrinkage necrosis, was actually first described by Kerr in this model. ${ }^{5,6}$ A reduction in size and number of hepatocytes, with the presence of Councilman bodies has been observed., ${ }^{7,8}$ DNA fragmentation in the ligated lobes has also been described, ${ }^{9}$ suggesting an implication of programed

Correspondence: Dr Y Horsmans, MD, PhD, Department of Gastroenterology, Saint Luc University Hospital, Avenue Hippocrate 10, Brussels 1200, Belgium.

E-mail: horsmans@gaen.ucl.ac.be

Received 26 September 2003; revised 26 January 2004; accepted 27 January 2004; published online 29 March 2004 cell death in the process of atrophy. However, these techniques have in the past few years been criticized for their lack of sensitivity and specificity. ${ }^{10}$

Three main pathways lead to apoptotic death of the cell. The death receptor-mediated pathway leads to caspase 8 activation. The mitochondrial dysfunction-mediated pathway, through cytochrome $c$ release into the cytosol, and the endoplasmic reticulum stress-triggered pathway, through caspase 12 activation, ${ }^{11,12}$ both lead to caspase 9 activation.

The first aim of this study was to determine the role of apoptosis in liver atrophy after PBL and to clarify the molecular mechanisms involved in the process. In order to do this, we analyzed tumor necrosis factor $\alpha$ (TNF- $\alpha$ ) concentration and caspase 8 activation to assess the death receptor-mediated pathway. Expression of proapoptotic protein Bax and antiapoptotic proteins Bcl-2 and $\mathrm{Bcl}_{\mathrm{L}}$ in mitochondrial fractions, as well as cytochrome $C$ release from mitochondria into the cytosol were measured to explore the mitochondrial pathway. Caspase 9 activation, a downstream event to the mitochondrial pathway as well as to caspase 12 activation, was also assessed. Finally, apoptotic effector caspase 3, activated by the three pathways, was assessed by fluorigenic activity assays. 
As recently shown, pretreatment of rats with retrorsine, a pyrrolizidine alkaloid known to block the proliferation of differentiated liver cells, leads to a block in the hyperplasia of the nonligated lobes, normally observed after PBL. ${ }^{13}$ Moreover, this pretreatment decreases atrophy of the ligated lobes compared to untreated rats. This suggests that some homeostatic mechanism inhibits atrophy in an attempt to maintain a stable liver mass in spite of the inability for the nonligated lobes to proliferate in a normal way. The second aim of this study was to assess the importance of the activation of apoptotic pathways in the liver of retrorsine-treated rats after PBL. This was achieved by comparison of TNF- $\alpha$ concentration and caspases-8, -9 and -3 activation in the anterior liver lobes of retrorsine-treated and untreated rats after PBL.

\section{Materials and methods}

\section{Animals and Experimental Design}

Male Wistar rats $(180 \pm 20 \mathrm{~g})$ were purchased from Charles River Laboratories, Brussels, Belgium. They were maintained on an automatic $12 \mathrm{~h}$ light/dark cycle and were fed standard rat chow (AO4, Usine d'Alimentation Rationnelle, Epinay-sur-Orge, France) and water ad libitum.

After 1 week of acclimatization, rats were randomized to receive two intraperitoneal injections, separated by a 2-week interval, of either retrorsine (Sigma-Aldrich, Bornem, Belgium) $(30 \mathrm{mg} / \mathrm{kg})$ or saline. Retrorsine was dissolved in $\mathrm{HCl}(\mathrm{pH} 2.5)$ followed by neutralization by $\mathrm{NaOH} 0.1 \mathrm{~N}$, as described. ${ }^{14,15}$

At 4 weeks after the second injection, PBL was performed as described ${ }^{3}$ and four to eight animals per group were killed at 0, $30 \mathrm{~min}, 3,5,12,24,48,72$ and $168 \mathrm{~h}$ after PBL. Livers were excised and samples of anterior and posterior lobes were immersed in $4 \%$ buffered formaldehyde for histological and immunohistochemical analysis. The remaining parts were snap-frozen in liquid nitrogen and stored at $-80^{\circ} \mathrm{C}$ for future use.

All animals received humane care in compliance with the University of Louvain regulations.

\section{Liver Histology}

Formalin-fixed, paraffin-embedded tissue was sectioned $(5 \mu \mathrm{m})$ and stained with hematoxylin and eosin according to standard procedures.

\section{Cellular Extracts}

Whole cell lysates were obtained by incubating $200 \mathrm{mg}$ of tissue at $4^{\circ} \mathrm{C}$ for $30 \mathrm{~min}$ in a buffer consisting of $50 \mathrm{mM}$ Tris-HCl, $\mathrm{pH} 7.6,0.1 \%$ Triton $\mathrm{X}-100,5 \mathrm{mM}$ EDTA, $250 \mathrm{mM} \mathrm{NaCl}, 50 \mathrm{mM} \mathrm{NaF}$, $0.1 \mathrm{mM} \mathrm{Na} \mathrm{VO}_{4}, 1 \mathrm{mM}$ PMSF, $10 \mu \mathrm{g} / \mathrm{ml}$ leupeptine and $0.5 \mu \mathrm{g} / \mathrm{ml}$ aprotinine. After a $10 \mathrm{~min}$ centrifugation at $10000 \mathrm{~g}$ at $4^{\circ} \mathrm{C}$, the supernatant was collected and frozen in aliquots at $-80^{\circ} \mathrm{C}$.

Cytosolic proteins were prepared by gently homogenizing $100 \mathrm{mg}$ of tissue on ice with a glass Dounce homogenizer and a tight glass pestle in $750 \mu \mathrm{l}$ of a buffer containing $250 \mathrm{mM}$ sucrose, $20 \mathrm{mM}$ Hepes buffer, $10 \mathrm{mM} \mathrm{KCl}, 1 \mathrm{mM}$ EGTA, $1 \mathrm{mM}$ EDTA, $1.5 \mathrm{mM} \mathrm{MgCl} 2,1 \mathrm{mM}$ DTT, $0.1 \mathrm{mM}$ PMSF, $1 \mathrm{mg} / \mathrm{ml}$ leupeptine and $1 \mathrm{mg} / \mathrm{ml}$ antipain. After a $20 \mathrm{~min}$ incubation at $4^{\circ} \mathrm{C}$, the homogenate was spun at $10000 \mathrm{~g}$ for $15 \mathrm{~min}$ at $4^{\circ} \mathrm{C}$ and the supernatant was collected and frozen in working aliquots at $-80^{\circ} \mathrm{C}$ for future use.

Mitochondria-enriched fractions were prepared by resuspending the pellet of the cytosolic fractions in $500 \mu \mathrm{l}$ of the same buffer, followed by sonication and freezing in aliquots at $-80^{\circ} \mathrm{C}$.

Rat thymus was homogenized with an Ultraturrax device in 10 times its volume of STM buffer (250 mM sucrose, $50 \mathrm{mM}$ Tris-HCl, $\mathrm{pH} 7.4,5 \mathrm{mM}$ $\mathrm{MgSO}_{4}, 1 \mathrm{mM}$ PMSF and $1 \mu \mathrm{g} / \mathrm{ml}$ aprotinine). The homogenate was filtered through four layers of gauze and stored in aliquots at $-80^{\circ} \mathrm{C}$ for use as a standard for Western blots.

Protein content in liver extracts was assessed using a BCA Protein Assay (Pierce Chemicals, Rockford, IL, USA) according to the manufacturer's instructions, with serum albumin as a standard.

\section{Western Blotting}

Between 30 and $100 \mu \mathrm{g}$ of cellular proteins were resolved on an SDS-PAGE gel and transferred to a PVDF membrane (Polyscreen, NEN Life Science Products, Boston, MA, USA) as previously described. ${ }^{16}$

Aspecific binding of antibodies to the blotted membrane was blocked by incubation for $1 \mathrm{~h}$ at room temperature in Tris-buffered saline $(50 \mathrm{mM}$ Tris, $150 \mathrm{mM} \mathrm{NaCl}, \mathrm{pH} 7.6$ ) containing $5 \%$ skimmed milk.

The following antibodies and incubation conditions were used: mouse monoclonal anti-Bcl-2 (C-2) antibody (sc-7382, Santa Cruz Biotechnology) 1/500 overnight at $4^{\circ} \mathrm{C}$, mouse monoclonal anti-Bcl- $\mathrm{X}_{\mathrm{L}}$ (H-5) antibody (sc-8392, Santa Cruz Biotechnology) $1 / 500$ overnight at $4^{\circ} \mathrm{C}$, mouse monoclonal anti-Bax (B-9) antibody (sc-7480, Santa Cruz Biotechnology) $1 / 500$ overnight at $4^{\circ} \mathrm{C}$, mouse monoclonal anticytochrome $c$ (A-8) antibody (sc-13156, Santa Cruz Biotechnology) $1 / 500$ for $2 \mathrm{~h}$ at room temperature, and peroxidase-conjugated goat anti-mouse and anti-rabbit IgGs (Jackson Immunoresearch, West Grove, PA, USA) 1/20000-1/30000 for $1 \mathrm{~h}$ at room temperature. All incubations were carried out in Tris-buffered saline containing 1\% skimmed milk.

The antigen-antibody reaction was visualized using the Renaissance Enhanced Luminol Reagent (NEN Life Science products) and exposure of the 
membranes to X-Omat Blue XB-1 films (Kodak Scientific Imaging, Rochester, NY, USA) for 1-5 min.

The amount of immunoreactive protein was quantified using the Gel Doc 2000 scanning device (Bio Rad, Nazareth, Belgium).

For all Western blots, individual values were expressed in percentage of the mean of three standards (thymus homogenate) that were resolved on each gel.

Equal protein loading and complete transfer to the membrane were checked by Coomassie blue staining of gels and membranes.

\section{Caspase 3 Activity Assay}

Caspase 3 activity was assessed in cell lysates using the fluorogenic substrate Ac-DEVD-AFC (Alexis Biochemicals, Lausen, Switzerland), which is cleaved enzymatically by caspase 3 , releasing free AFC which produces a blue-green fluorescence.

Cell lysates $(75 \mu \mathrm{l})$ were incubated in a buffer containing $10 \mathrm{mM}$ Hepes, $2 \mathrm{mM}$ EDTA, 0.1\% CHAPS and $5 \mathrm{mM}$ DTT, in the presence of $10 \mu \mathrm{l}$ of substrate. Fluorescence was measured in each sample at $0 \mathrm{~min}$ and every $30 \mathrm{~min}$ for $120 \mathrm{~min}$ in a fluorimeter with excitation and emission wavelengths of 400 and $505 \mathrm{~nm}$ respectively. Caspase 3 activity in the sample was then calculated by the increase in fluorescence over time, compared to a calibration curve prepared with AFC (Sigma), and expressed per microgram protein in the sample, per minute.

Specificity of the reaction was ensured by adding the caspase 3 inhibitor Z-DEVD-FMK (PharMingen, San Diego, USA) which selectively inhibits cleavage of Ac-DEVD-AFC.

Caspase 3 activity was measured in four to seven rats per group, both in anterior and posterior liver lobes of retrorsine-treated and untreated rats.

\section{Caspase 8 and 9 Activity Assays}

Caspase 8 and 9 activities were assessed in cell lysates using the ApoAlert Caspase 8 and Caspase 9 Fluorescrent Assay kits (Clontech Laboratories, Palo Alto, CA, USA) according to the manufacturer's instructions.

Briefly, cell lysates $(75 \mu \mathrm{l})$ were incubated in reaction buffer for $1 \mathrm{~h}$ at $37^{\circ} \mathrm{C}$ in the presence of $5 \mu \mathrm{l}$ of IETD-AFC, which is enzymatically cleaved by caspase 8 or LEHD-AMC, which is cleaved by caspase 9, releasing AFC or AMC, respectively.

Fluorescence was measured in each sample at $0 \mathrm{~min}$ and every $30 \mathrm{~min}$ for $120 \mathrm{~min}$ in a fluorimeter with excitation and emission wavelengths of 400 and $505 \mathrm{~nm}$, respectively, for AFC and 380 and $460 \mathrm{~nm}$, respectively for AMC.

Caspase 8 and 9 activities were then calculated by the increase in fluorescence over time, compared to calibration curves, and expressed per microgram protein in the sample, per minute.
Specificity of the reaction was ensured by adding the caspase 8 and 9 inhibitors IETD-FMK and LEHD$\mathrm{CHO}$, respectively.

Caspase 8 and 9 activities were measured in four to five rats per group both in the anterior and posterior liver lobes of retrorsine-treated and untreated rats.

\section{TNF- $\alpha$ ELISA}

TNF- $\alpha$ concentrations were assessed on $100 \mu$ l of cytosolic extracts of the anterior lobes of retrorsinetreated and untreated rats before, $30 \mathrm{~min}$ and 3,5 and $12 \mathrm{~h}$ after PBL using the Quantikine M rat TNF- $\alpha$ ELISA assay (R\&D Systems, Abingdon, UK), according to the manufacturer's instructions.

For each rat, TNF- $\alpha$ concentration was determined as the average of two assays, performed on the same microplate. Microplates were read in a microplate reader at $450 \mathrm{~nm}$ with correction wavelength set at $540 \mathrm{~nm}$. Concentration was then calculated from the optical density by using a standard curve as described in the manufacturer's instructions, and the values were expressed as $\mathrm{pg} / \mathrm{mg}$ protein in the sample.

\section{Statistical Analysis}

Data are expressed as mean \pm s.e.m. Student's unpaired $t$-test was used to compare values between retrorsine-treated and untreated rats and between pre- and postsurgery levels. Student's paired $t$-test was used to compare results between anterior and posterior lobes of the same animals.

\section{Results}

Weight of the Anterior and Posterior Lobes after PBL in Retrorsine-Treated and Untreated Rats (Figure 1)

Before PBL, there were no statistically significant differences in the weight of the anterior or posterior lobes between retrorsine-treated and untreated animals. After PBL, a decrease of the weight of the anterior lobes (Figure 1a) was found in retrorsinetreated as well as untreated rats when compared to their weight before surgery. This decrease was statistically significant from 24 to $168 \mathrm{~h}$ after PBL. When comparing retrorsine-treated and untreated rats, no differences in the weight of the anterior lobes were found at 24,48 and $72 \mathrm{~h}$ after PBL. At $168 \mathrm{~h}$ after PBL, the weight of the anterior lobes was significantly higher in retrorsine-treated than in untreated animals $(0.76 \pm 0.05$ vs $0.52 \pm 0.04 \mathrm{~g} / 100 \mathrm{~g}$ body weight, $P<0.01)$. The weight of the posterior liver lobes (Figure 1b) increased significantly after surgery in both retrorsine-treated and untreated rats. However, the weight gain was significantly impaired in rats pretreated with retrorsine. This difference 

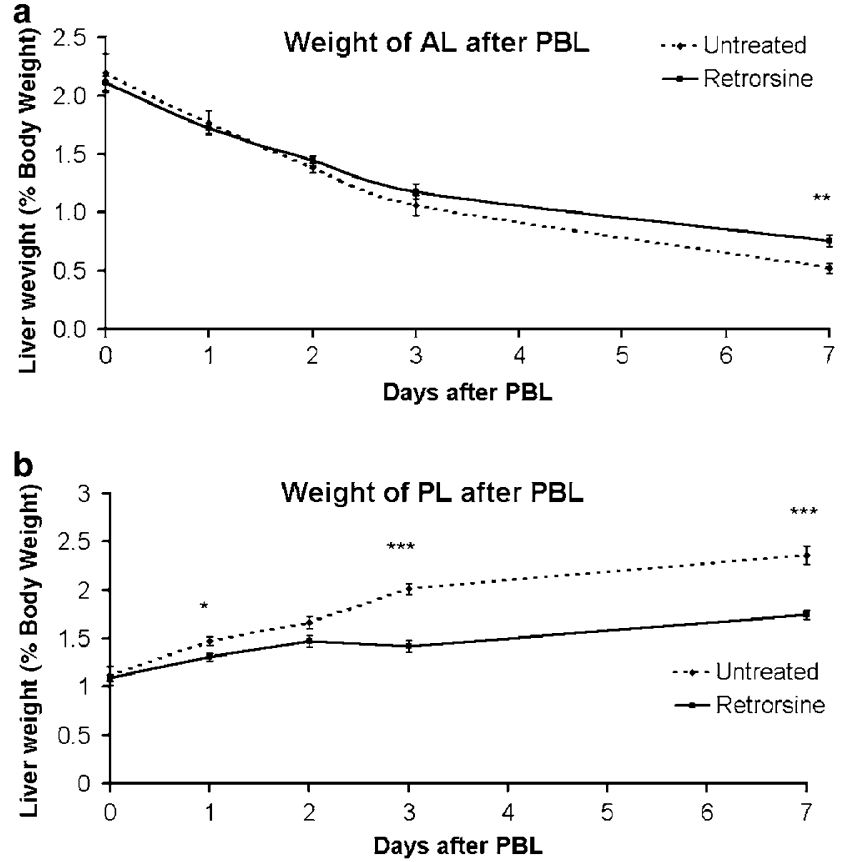

Figure 1 Weight of the anterior and posterior liver lobes after PBL. Evolution of the weight of the anterior (a) and posterior (b) liver lobes after PBL, expressed as percentage of body weight, in retrorsine-treated and untreated animals. ${ }^{*} P<0.05,{ }^{*} P<0.01$, ${ }^{* * *} P<0.001$, Student's unpaired $t$-test, retrorsine treated vs untreated rats. Data are expressed as mean \pm s.e.m. with $n=5-8$ per group.

was still present at $168 \mathrm{~h}$ after PBL $(1.74 \pm 0.05$ vs $2.36 \pm 0.09 \mathrm{~g} / 100 \mathrm{~g}$ body weight, $P<0.001)$.

\section{Liver Histology (Figures 2 and 3)}

Megalocytes containing large and dense nuclei were observed in all lobes of the liver of retrorsine-treated rats both before and after surgery and were never observed in the liver of untreated rats. At $24 \mathrm{~h}$ after PBL, acidophilic degeneration of some isolated hepatocytes could be found in the anterior hepatic lobes of both untreated and retrorsine-treated rats (Figure 2a and b). After $48 \mathrm{~h}$, this histological feature was more pronounced, both in retrorsineuntreated and treated rats, with rare apoptotic bodies lying free in the cell plates. Three days after PBL, the picture was unchanged in retrorsinetreated rats whereas lots of apoptotic bodies, sometimes arranged in small clusters, could be seen in untreated rats (Figure 2c and d). After 7 days, the number of apoptotic bodies in the anterior hepatic lobes of untreated rats decreased (Figure 2e), accompanied by a decrease in the size of the lobules. By contrast, there was no decrease in the size of the hepatic lobules in retrorsine-exposed rats, in which some apoptotic bodies were still present (Figure 2f).
In the posterior lobes, mitoses appeared at $48 \mathrm{~h}$ in untreated rats but not in retrorsine-treated rats (Figure 3a and b). The histology of the posterior hepatic lobes of retrorsine-treated rats at 72 and $168 \mathrm{~h}$ after PBL was characterized by the emergence of clusters of small cells (Figure 3d and $\mathrm{f}$ ) that were never detected in the posterior hepatic lobes of untreated rats (Figure 3c-e). Some mitoses could be observed in those clusters (Figure $3 \mathrm{~d}$ and $\mathrm{f}$.

\section{Bax, Bcl-2 and Bcl- $\mathrm{X}_{\mathrm{L}}$ Western Blotting (Figure 4)}

In order to assess the activation of the mitochondrial pathway in untreated rats after PBL, Bax, Bcl-2 and Bcl- $\mathrm{X}_{\mathrm{L}}$ protein expressions were estimated in the mitochondrial fractions of the anterior and posterior liver lobes of four rats per group before and 24, 48, 72 and $168 \mathrm{~h}$ after PBL.

In the anterior, ligated lobes, Bax (Figure 4a) increased significantly at $48 \mathrm{~h}$ after PBL, before returning to normal, pre-surgery levels. In the posterior liver lobes, it remained stable until $48 \mathrm{~h}$ after surgery, then rose at $72 \mathrm{~h}$, followed by a return to basal levels at $168 \mathrm{~h}$ after surgery. Bax was significantly higher in the anterior than in the posterior lobes at $48 \mathrm{~h}$, while it was significantly higher in the posterior lobes at $72 \mathrm{~h}$.

Bcl-2 (Figure 4b) rose in the anterior lobes after $\mathrm{PBL}$, the difference reaching statistical significance at $48 \mathrm{~h}$, with a maximum level at $168 \mathrm{~h}$. In the posterior lobes, only a slight increase of Bcl-2 was found after PBL from $24 \mathrm{~h}$ after surgery, remaining stable in all subsequent investigated time points. Bcl-2 protein expression was significantly higher in the anterior than in the posterior liver lobes at 48 and $168 \mathrm{~h}$ after surgery.

In the anterior as well as the posterior lobes, Bcl$\mathrm{X}_{\mathrm{L}}$ (Figure 4c) rose after PBL, reaching a statistically significant peak at $48 \mathrm{~h}$, before returning to basal levels at 72 and $168 \mathrm{~h}$. At no time were the differences in Bcl- $\mathrm{X}_{\mathrm{L}}$ protein levels between anterior and posterior liver lobes significant.

\section{Cytochrome $c$ Release (Figure 5)}

Cytochrome $c$ levels were measured in the cytosol of anterior and posterior liver lobes of four rats per group before and 24, 48, 72 and $168 \mathrm{~h}$ after PBL. In the anterior lobes, levels of cytochrome $c$ rose significantly at $24 \mathrm{~h}$ after surgery, remaining stable at 48 and $72 \mathrm{~h}$, then returning to presurgery levels at $168 \mathrm{~h}$. In the posterior lobes, cytochrome $c$ remained stable at $24 \mathrm{~h}$ after PBL, followed by a gradual increase, a peak at $72 \mathrm{~h}$ and a return to basal levels at $168 \mathrm{~h}$. Cytochrome $c$ was significantly higher in the cytosol of anterior than of posterior liver lobes at 24 and $48 \mathrm{~h}$ after surgery. 

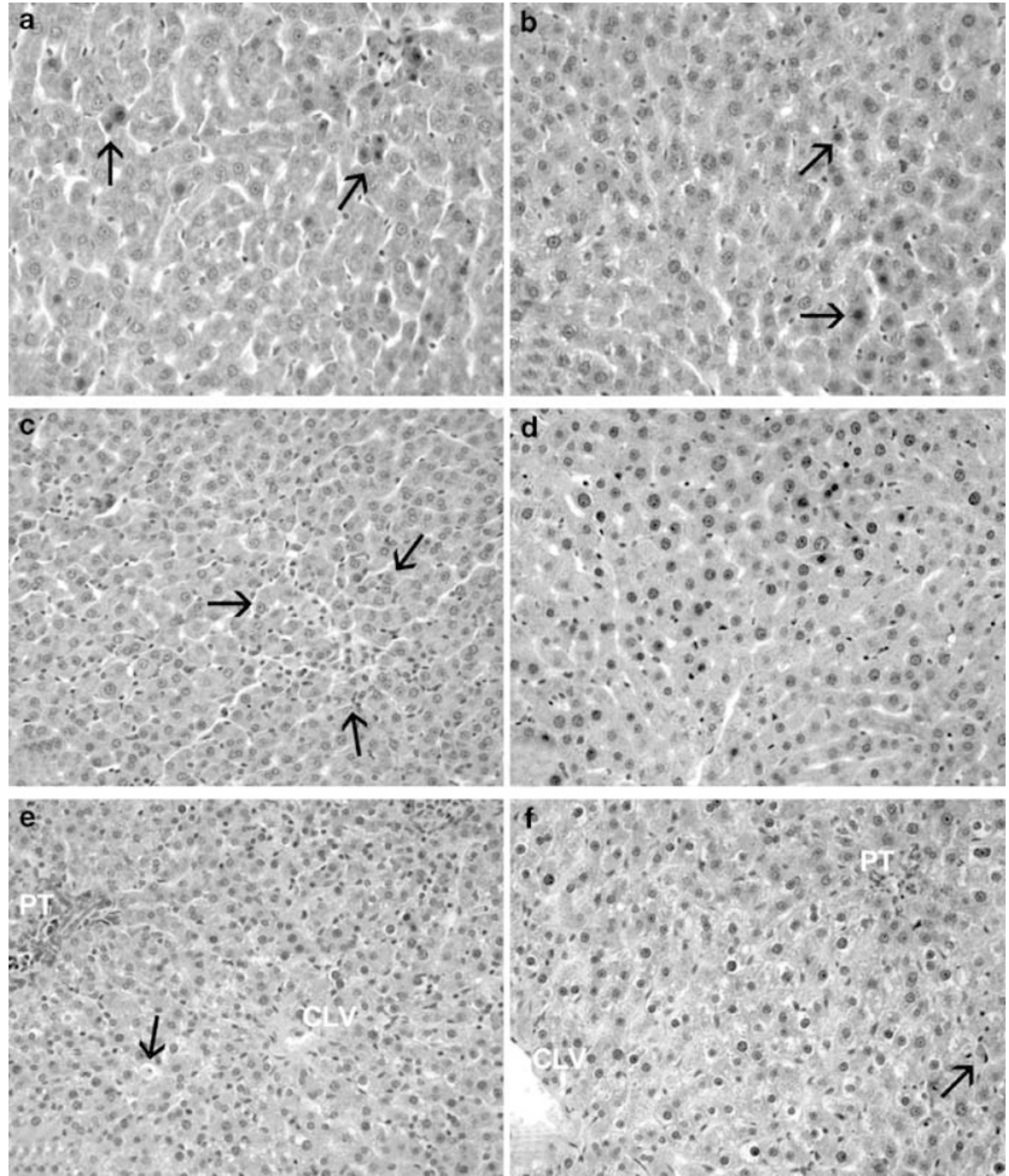

Figure 2 Histologic appearance of the anterior hepatic lobes of untreated (a, $\mathbf{c}$ and $\mathbf{e}$ ) and retrorsine-treated rats (b, d and f) At 24,72 and $168 \mathrm{~h}$ after PBL (Hematoxylin-eosin, X210). At $24 \mathrm{~h}$ after PBL, acidophilic degeneration of some hepatocytes is seen in both untreated (a) and treated rats (b) (arrows). At $72 \mathrm{~h}$, clusters of apoptotic bodies are present in untreated rats (c, arrows) but such clusters cannot be found in retrorsine-treated rats (d). After $168 \mathrm{~h}$, the size of the hepatic lobules is decreased in untreated rats (e) but not in retrorsinetreated rats (f). In both, some apoptotic bodies are still present (arrows). Note the presence of megalocytes in retrorsine-treated rats only. PT portal tract; CLV centrolobular vein.

\section{TNF- $\alpha$ Concentration}

TNF- $\alpha$ concentration was measured in the cytosol of the anterior liver lobes of three untreated and three retrorsine-treated rats per group before, $30 \mathrm{~min}$ and 3,5 and $12 \mathrm{~h}$ after PBL.

In untreated rats, basal TNF- $\alpha$ was low $(14.3 \pm 1.2 \mathrm{pg} / \mathrm{mg}$ protein). A two to three-fold increase in TNF- $\alpha$ concentration was observed after PBL from $30 \mathrm{~min}$ to $5 \mathrm{~h}$, the difference vs basal levels reaching statistical significance at $30 \mathrm{~min}$ $(22.5 \pm 2.2 \mathrm{pg} / \mathrm{mg}$ protein, $P=0.03$ Student's $t$-test vs basal levels) and $3 \mathrm{~h}(37.9 \pm 6.6 \mathrm{pg} / \mathrm{mg}$ protein, $P=0.03$ Student's $t$-test vs basal levels). By $12 \mathrm{~h}$ after $\mathrm{PBL}$, the concentration of TNF- $\alpha$ had returned to basal levels. In retrorsine-treated rats, a similar evolution of TNF- $\alpha$ was observed as in untreated rats.

\section{Caspase -9, -8 and -3 Activities (Figures 6 and 7)}

Caspase-9, -8 and -3 activities were measured on whole cell lysates of anterior and posterior liver lobes of four to seven rats per group before and 24, 48, 72 and $168 \mathrm{~h}$ after PBL, both in retrorsine-treated and untreated rats.

In the anterior lobes of untreated rats, caspase 9 activity rose gradually from 24 to $168 \mathrm{~h}$ after surgery, when the maximum levels were found. The difference vs basal levels reached statistical significance from 48 to $168 \mathrm{~h}$ after surgery (Figure 6a). In 

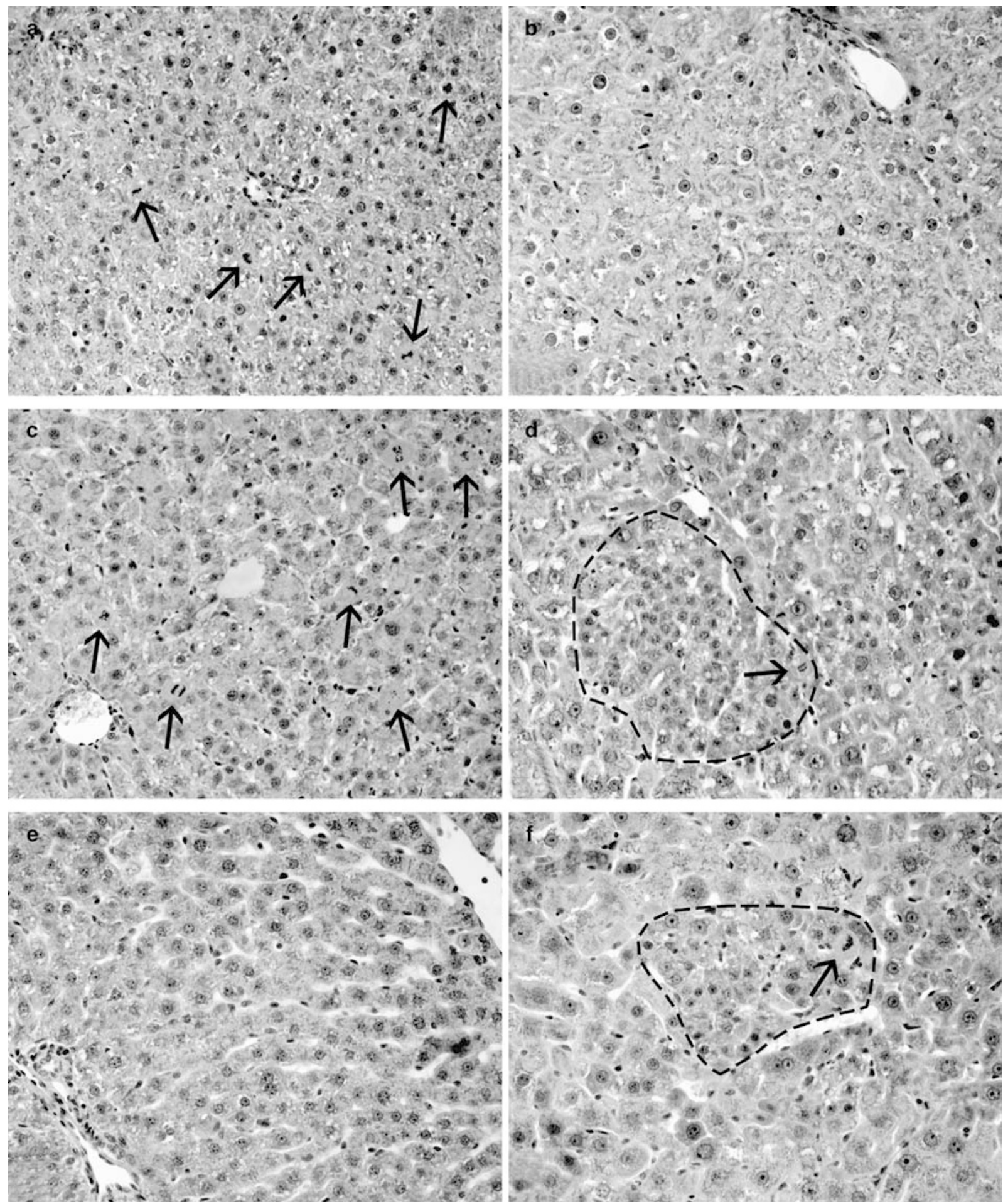

Figure 3 Histologic appearance of the posterior hepatic lobes of untreated (a, $\mathbf{c}$ and $\mathbf{e}$ ) and retrorsine-treated rats (b, $\mathbf{d}$ and $\mathbf{f})$ at 48,72 and $168 \mathrm{~h}$ after PBL (Hematoxylin-eosin, X210). At $48 \mathrm{~h}$ after PBL, mitoses appear in untreated rats (a, arrows) but not in retrorsine-treated rats (b). At $72 \mathrm{~h}$, the liver of untreated rats exhibits a lot of mitoses (c, arrows) whereas in retrorsine-treated rats (d), only rare mitoses are observed (arrow), almost exclusively localized in emerging clusters of small cells (dotted line). After $168 \mathrm{~h}$, in untreated rats (e), the histology of the posterior hepatic lobes is unremarkable whereas in retrorsine-treated rats (f), the particular clusters of small cells (dotted line) with mitoses (arrow) are still present.

contrast, there was no significant change in caspase 9 activity in the posterior liver lobes after surgery. As a consequence, caspase 9 activity was higher in the anterior than in the posterior liver lobes from 48 to $168 \mathrm{~h}$ after surgery, the difference reaching statistical significance at $168 \mathrm{~h}$ post-PBL. 


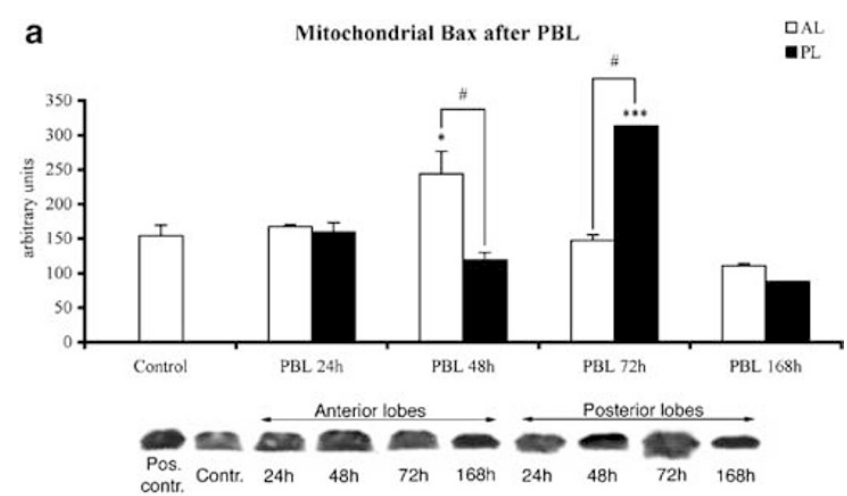

b
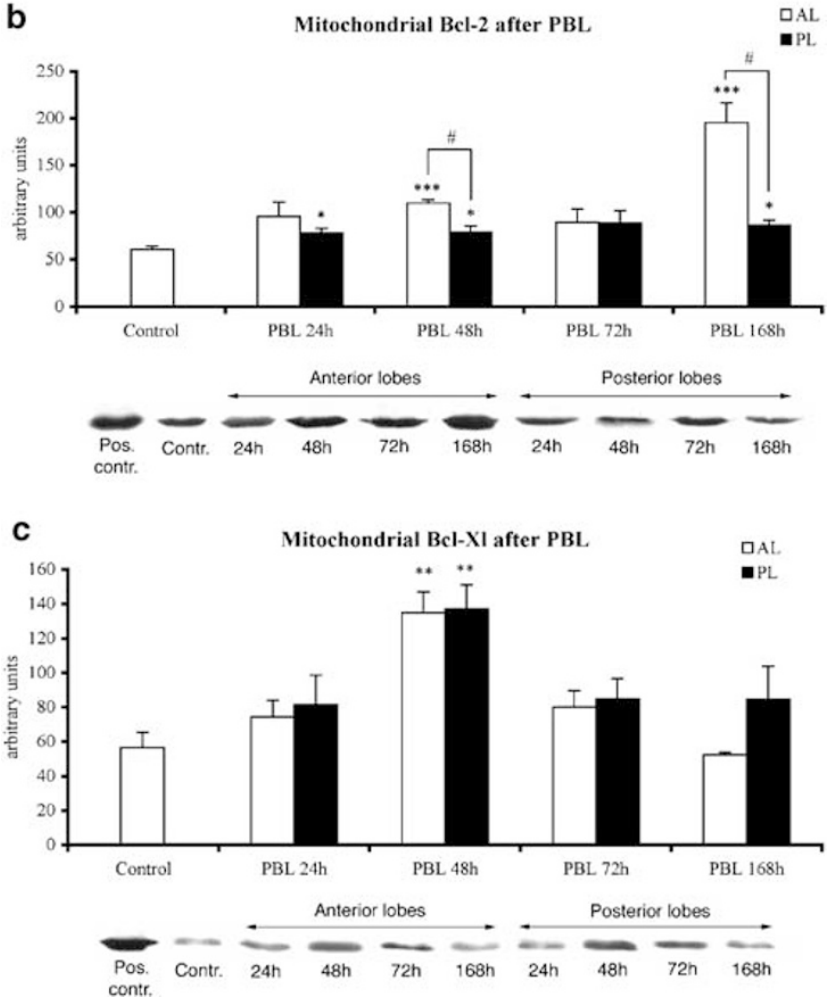

Figure 4 Bax, Bcl-2 and Bcl- $\mathrm{X}_{\mathrm{L}}$ protein after PBL. Bax (a), Bcl-2 (b) and Bcl- $\mathrm{X}_{\mathrm{L}}$ (c) were evaluated by Western blotting on mitochondrial fractions of the anterior and posterior lobes of four rats per group before and $24,48,72$ and $168 \mathrm{~h}$ after PBL. ${ }^{*} P<0.05$, $* * * P<0.001$ Student's unpaired $t$-test vs pre-PBL levels. ${ }^{*} P<0.05$ Student's paired $t$-test anterior vs posterior lobes. Data are expressed as mean \pm s.e.m. with $n=4$ per group.

In retrorsine-treated rats, only a slight increase of caspase 9 activity was observed in the anterior lobes, peaking at $48 \mathrm{~h}$ after surgery (Figure $7 \mathrm{a}$ ), while no significant changes were found in their posterior lobes (Figure 8). Therefore, caspase 9 activity was significantly higher in the anterior lobes of untreated than of retrorsine-treated rats at 72 and $168 \mathrm{~h}$ after PBL. No statistically significant differences in caspase 9 activity were found in the posterior lobes after PBL between retrorsine-treated and untreated rats.

Caspase 8 activity rose after PBL in the anterior lobes of untreated rats (Figure 7b), significantly so at

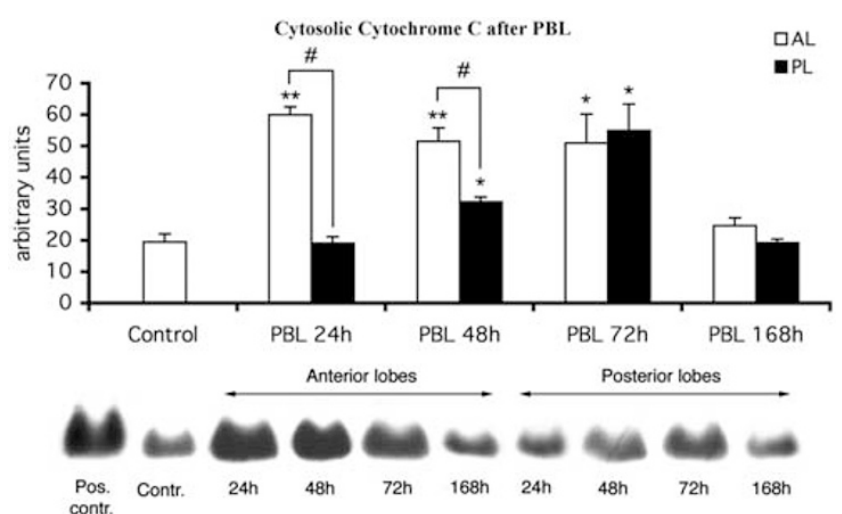

Figure 5 Cytosolic cytochrome $c$ protein after PBL. Cytochrome $c$ was evaluated by Western blotting on cytosolic fractions of the anterior and posterior lobes of four rats per group before and 24, 48, 72 and $168 \mathrm{~h}$ after PBL. ${ }^{*} P<0.05,{ }^{*} P<0.01$ Student's unpaired $t$-test $v s$ pre-PBL levels. ${ }^{\#} P<0.05$ Student's paired $t$-test anterior vs posterior lobes. Data are expressed as mean \pm s.e.m. with $n=4$ per group.
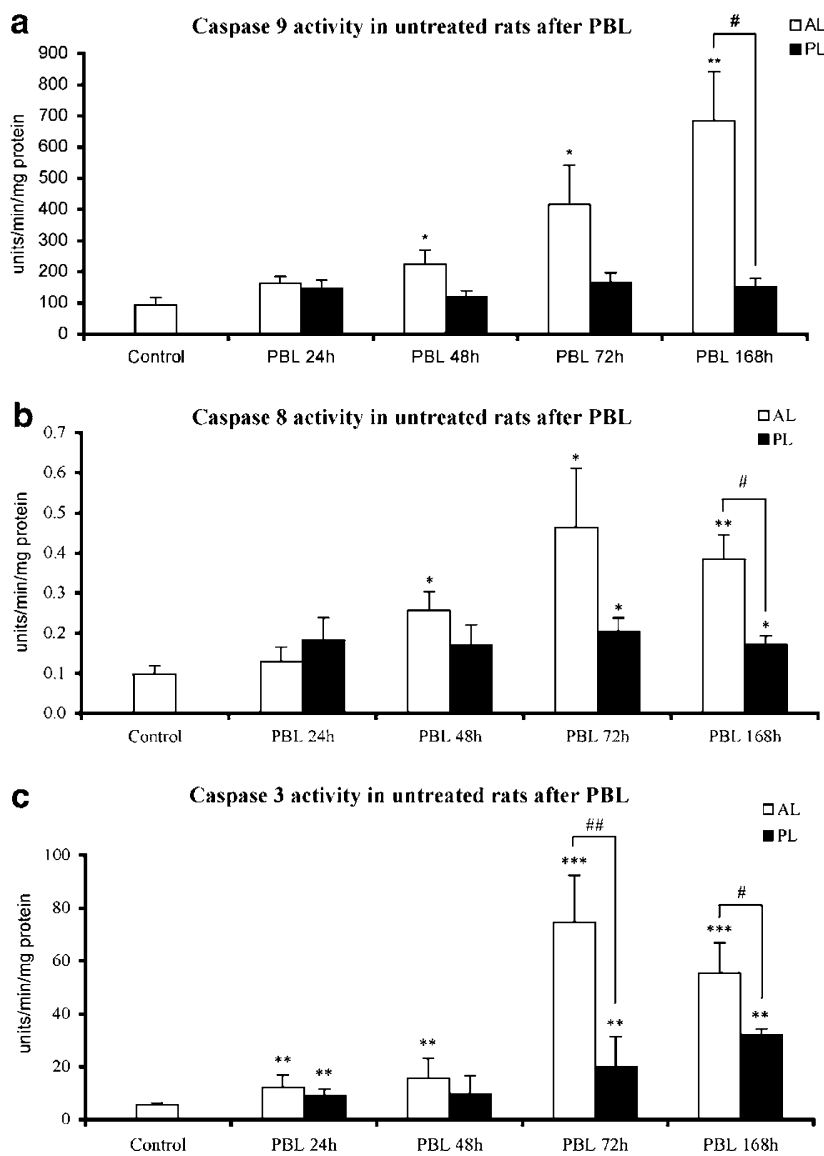

Figure 6 Caspase-9, -8 and -3 activities in anterior and posterior lobes after PBL. Caspase-9 (a), -8 (b) and -3 (c) activities were measured by fluorimetric assays in four to seven rats per group before and $24,48,72$ and $168 \mathrm{~h}$ after PBL. ${ }^{*} P<0.05,{ }^{*}{ }^{*} P<0.01$, $* * * P<0.001$, Student's unpaired $t$-test vs pre-PBL levels. ${ }^{\#} P<0.05,{ }^{\# \#} P<0.01$, Student's paired $t$-test anterior vs posterior lobes. Data are expressed as mean \pm s.e.m. with $n=4-7$ per group. 

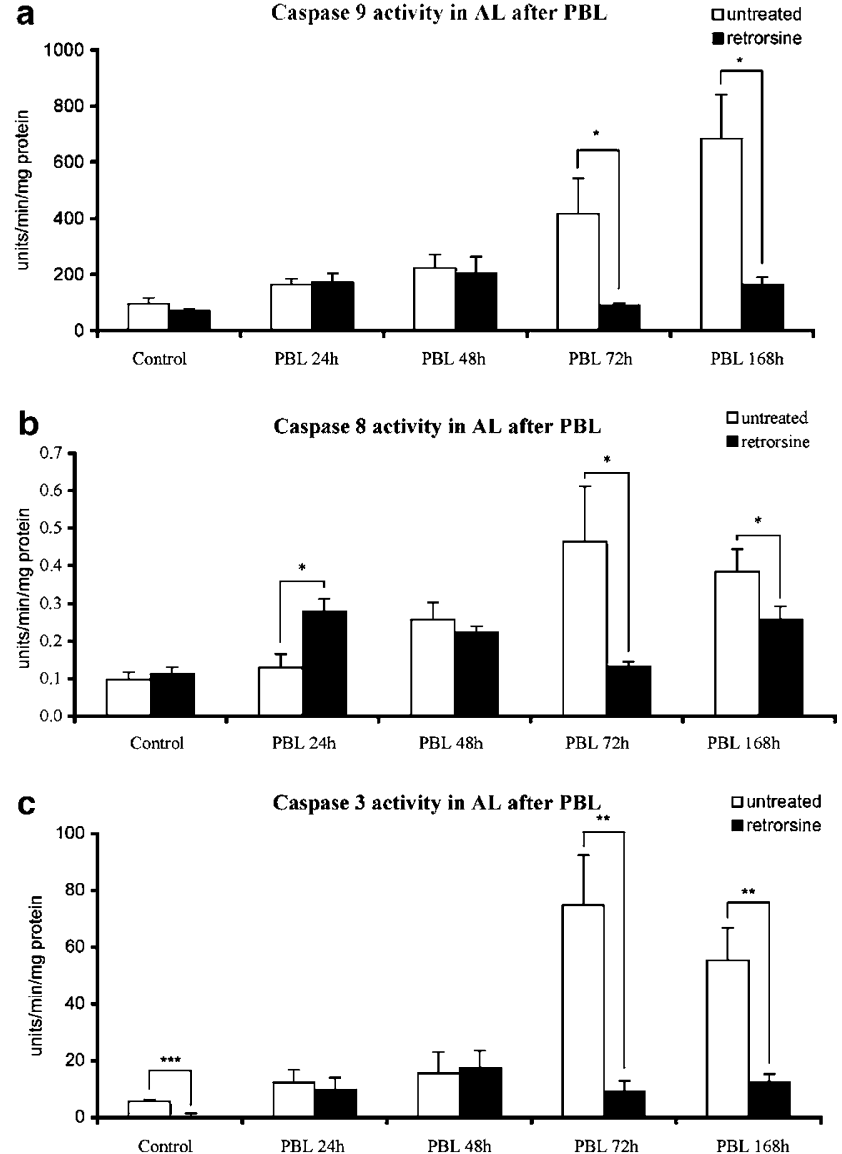

Figure 7 Caspase-9, -8 and -3 activities in the anterior lobes of retrorsine-treated and untreated rats after PBL. Caspase-9 (a), -8 (b) and -3 (c) activities were measured by fluorimetric assays in the anterior lobes of four to seven rats per group before and 24, 48, 72 and $168 \mathrm{~h}$ after PBL. Data in the open bars are the same as the data in the open bars of Figure 6 (same animals, same experiments). $\quad{ }^{*} P<0.05, \quad{ }^{*} P<0.01, \quad{ }^{*}{ }^{*} P<0.001$, Student's unpaired $t$-test untreated $v s$ retrorsine-treated rats. Data are expressed as mean \pm s.e.m. with $n=4-7$ per group.

48,72 and $168 \mathrm{~h}$, and peaked at $72 \mathrm{~h}$. In the posterior liver lobes of untreated rats, caspase 8 activity rose only slightly after PBL, the difference vs basal levels reaching statistical significance at 72 and $168 \mathrm{~h}$ postsurgery. However, the levels of caspase 8 activity in these rats were higher in the anterior than in the posterior liver lobes at 48, 72 and $168 \mathrm{~h}$, the difference reaching statistical significance at $168 \mathrm{~h}$.

In the anterior lobes of retrorsine-treated rats, caspase 8 activity rose after PBL, remaining above baseline levels at all time points (Figure 7b). However, the levels of caspase 8 activity reached higher levels in untreated rats, the difference reaching statistical significance at 72 and $168 \mathrm{~h}$. In the posterior lobes of retrorsine-treated rats, only a slight increase of caspase 8 activity was found, reaching statistical significance at 48 and $72 \mathrm{~h}$ after PBL. At no time were the levels of caspase 8 activity in the posterior lobes different when comparing retrorsine-treated and untreated rats (Figure 8).

Effector caspase 3 activity rose steadily from 24 to $72 \mathrm{~h}$ after surgery in the anterior lobes of untreated rats, and remained at a high level at $168 \mathrm{~h}$ (Figure 7c). In the posterior lobes of these rats, caspase 3 activity also rose moderately, the difference compared to basal levels being statistically significant at 24, 72 and $168 \mathrm{~h}$ after surgery. However, caspase 3 activity was significantly higher in the anterior than in the posterior lobes at 72 and $168 \mathrm{~h}$.

In the anterior lobes of retrorsine-treated rats, an increase in caspase 3 activity after PBL was also observed, but reaching only a fraction of the levels observed in untreated rats (Figure 7c). The difference between retrorsine-treated and untreated rats was found to be statistically significant before and 72 and $168 \mathrm{~h}$ after surgery. In the posterior lobes of retrorsine-treated animals, caspase 3 activity increased slightly above basal levels after PBL, reaching statistical significance only at $168 \mathrm{~h}$ after PBL (Figure 8).

\section{Discussion}

After PBL in rats, atrophy of the anterior, ligated liver lobes occurs rapidly, through a reduction in size as well as number of hepatocytes. ${ }^{5,7,8}$ Morphologically, Councilman bodies are found in the ligated lobes from 2 days after PBL, with a gradual decrease from day 3 to day $8 .{ }^{5} \mathrm{~A}$ decrease of $50 \%$ of the original weight has been described $48 \mathrm{~h}$ after PBL, while only one-third of the initial weight remains by the fourth day. ${ }^{17}$ More recently, DNA fragmentation was observed ${ }^{9}$ in the ligated lobes at different time points from 0 to $24 \mathrm{~h}$ after PBL by terminal deoxynucleotidyl transferase-mediated dUTP nick end labeling (TUNEL) assays and electrophoresis of DNA on agarose gels. However, these techniques are thought to be nonspecific of programed cell death. ${ }^{10}$

In this study, we describe the molecular mechanisms leading to the atrophy of portal blood-deprived liver lobes. We also provide evidence that the rate of atrophy by programed cell death can be controlled by homeostatic mechanisms, when compensatory proliferation in the nonligated lobes is made impossible by retrorsine poisoning.

Apoptosis is a tightly controlled process that is vital to maintain the balance between cell loss and cell production in normal tissue. ${ }^{18,19}$ Excessive apoptosis in the liver can lead to hepatic insufficiency, while failure of apoptosis is one of the prerequisites to develop cancer. ${ }^{20}$ In the past few years, understanding of the molecular mechanisms responsible for programed cell death has made significant advances.

Schematically, three main initiation pathways leading to the activation of effector proteases called caspases are found in the liver: ${ }^{11,12,21}$ the first one 

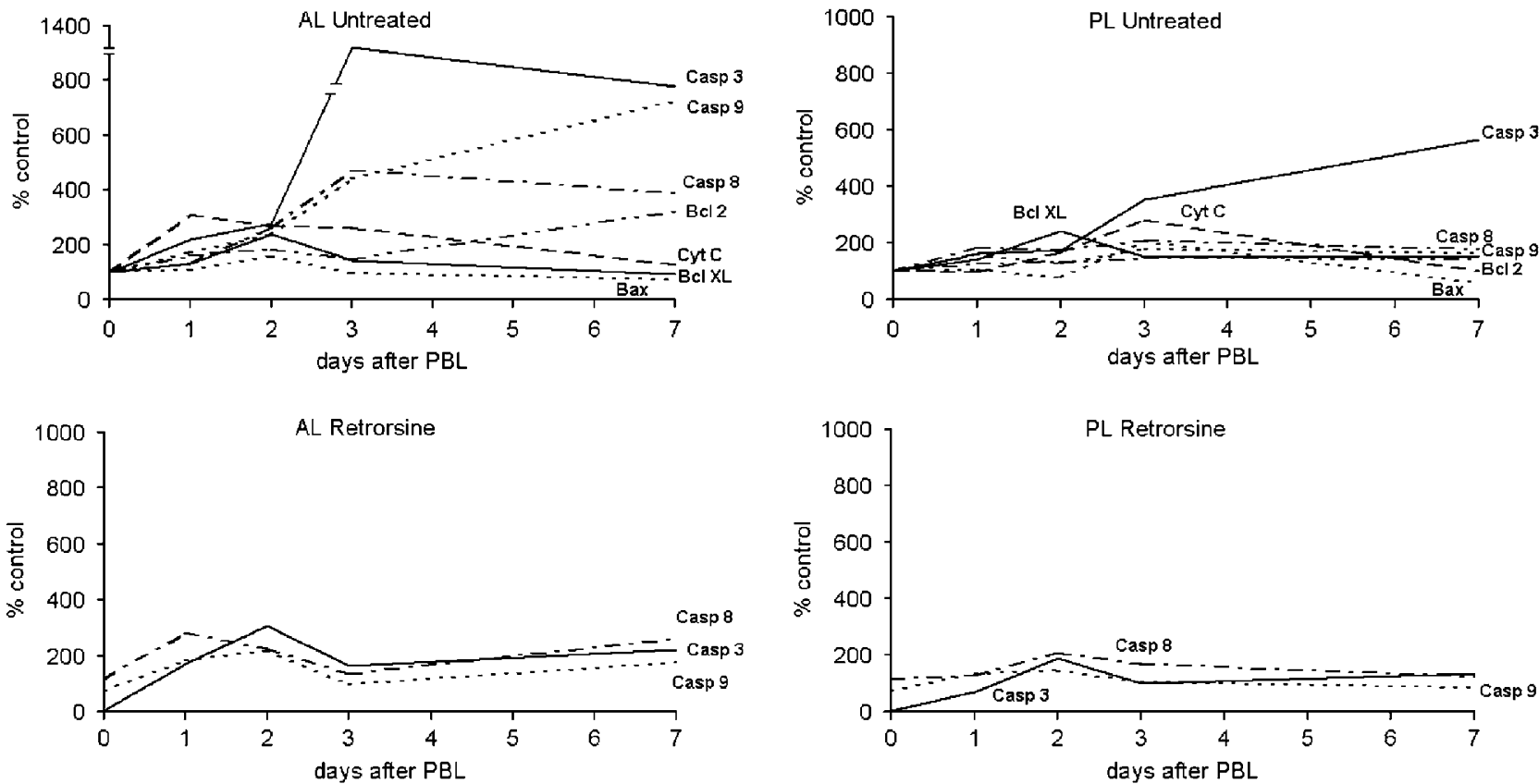

Figure 8 Comparison of results in the anterior and posterior lobes of retrorsine-treated and untreated rats. Line graphs showing the changes in caspase -8, -9 and -3 activities in the anterior and posterior lobes of retrorsine-treated and untreated rats after PBL, as well as the evolution of mitochondrial Bax, Bcl-2 and Bcl- $\mathrm{X}_{\mathrm{L}}$ and of cystosolic cytochrome $c$ in the anterior and posterior lobes of untreated rats at various time points after surgery. The line graphs represent an interpretation of an extensive set of data, and are not the specific data.

involves activation of death receptors, the second one is triggered by mitochondrial dysfunction and the last one by endoplasmic reticulum stress.

In this study, we investigated the death receptormediated pathway by measuring TNF- $\alpha$ concentration and by performing caspase 8 activation assays, and the mitochondrial pathway by proapoptotic Bax and anti-apoptotic Bcl-2 and Bcl- $\mathrm{X}_{\mathrm{L}}$ protein assessment in mitochondrial fractions and by cytochrome C release into the cytosol. Caspase 9 activation resulting from both cytochrome $c$ release and procaspase 12 activation by endoplasmic reticulum stress was also measured. Caspase 3 activation was chosen to assess the proteolytic activity of effector caspases. Histology of the anterior and posterior liver lobes of both retrorsine-treated and untreated rats was also carefully examined for the presence of apoptotic bodies.

Our results (Figure 8) show that apoptosis is induced in the anterior liver lobes of untreated rats after PBL. Mitochondrial proapoptotic Bax rises after PBL, with a peak at $48 \mathrm{~h}$, while antiapoptotic $\mathrm{Bcl}-2$ is maximal at $168 \mathrm{~h}$, when most of the atrophy has taken place. The significance of the earlier rise of antiapoptotic Bcl- $\mathrm{X}_{\mathrm{L}}$, which peaks at $48 \mathrm{~h}$, remains unclear, but the various members of the Bcl-2 family are known to form homo- and heterodimers, so that the relative amounts of pro- and antiapoptotic proteins seem to be more important than their absolute presence. ${ }^{22}$

Our experiments suggest an early proapoptotic trend (high Bax and low Bcl-2) followed by a late antiapoptotic trend (low Bax and high Bcl-2). This is associated to an early and prolonged release of cytochrome $c$ into the cytosol, followed by gradual caspase 9 activation. Taken together, these data show that the mitochondrial pathway is activated in the atrophying liver lobes after PBL. In addition to the mitochondrial pathway, endoplasmic reticulum stress could also contribute to caspase 9 activation, through the release of active caspase $12 .^{23}$

Caspase 8 is thought to be activated by the binding of death ligands such as TNF- $\alpha$ and Fas to death receptors. ${ }^{24,25}$ In the anterior lobes after PBL, we observed an early rise of TNF- $\alpha$ concentrations, followed by a progressive activation of caspase 8.

Both the mitochondrial and the death receptortriggered pathways leading to apoptosis are thus activated by the interruption of the inflow of portal blood, resulting in a massive induction of effector caspase 3. Histologically, apoptotic bodies were found in the anterior lobes of untreated rats from $48 \mathrm{~h}$ after PBL, showing that the activation of apoptotic pathways leads to actual apoptosis of hepatocytes.

To our knowledge, this study is the first one that describes the molecular mechanisms leading to liver atrophy after PBL.

In the posterior liver lobes, mitochondrial Bax was found to rise at $72 \mathrm{~h}$ thereafter decreasing to subbasal levels; in the meantime, Bcl-2 remained unchanged and Bcl- $\mathrm{X}_{\mathrm{L}}$ rose at $48 \mathrm{~h}$. Cytosolic cytochrome $c$ rose at $48 \mathrm{~h}$ after PBL, peaked at $72 \mathrm{~h}$ 
and returned to basal levels. No activation of caspase 9 above baseline was observed.

Caspase 8 activity rose slightly in the posterior lobes after PBL, the difference vs basal levels reaching statistical significance at 72 and $168 \mathrm{~h}$. Together with the activation of effector caspase 3, this suggests a late activation of the death receptor mediated pathway. These findings could be interpreted as a means of fine-tuning liver regeneration, as it has been suggested by others. ${ }^{26}$

In conclusion to the first part of this study, our data strongly support the fact that both the death receptor-mediated and the mitochondrial pathways are activated in the anterior, ligated liver lobes after PBL, showing that apoptosis accounts for the atrophy of these lobes.

In the second part of our experiments, we evaluated the influence of an inhibition of hepatocyte proliferation by retrorsine on liver atrophy. This alkaloid, when administered before proceeding to PBL, renders liver regeneration of the nonligated lobes impossible, but also significantly slows down atrophy of the portal blood deprived lobes. ${ }^{13}$ In order to do so, we compared caspase-8, -9 and -3 activities as well as histology of the anterior and posterior liver lobes after PBL in retrorsine-treated and untreated rats.

At $72 \mathrm{~h}$ after PBL, very few apoptotic bodies were found in the anterior lobes of retrorsine-treated rats, whereas many of these could be observed in untreated animals. In addition, we observed a significantly lower activity of caspases in the anterior lobes at 72 and $168 \mathrm{~h}$ when retrorsine had been administered to the animals. This could be explained by a direct toxic effect of retrorsine on caspase activation and/or of pro-caspase synthesis. Another way to interpret these observations is that homeostatic mechanisms inhibiting atrophy are operating in an attempt to maintain the total mass of the liver when proliferation of the nonligated lobes is impaired. This second hypothesis is supported by the fact that caspase- 8 and -9 activities in the posterior lobes are not significantly impaired by retrorsine treatment, ruling out a direct inhibitory effect of the alkaloid on the activity of these proteolytic enzymes.

The mechanisms responsible for such an inter-relation between anterior and posterior lobes are still to be discovered, but it is tempting to think that some extrahepatic, circulating factor is involved.

In conclusion, our data show that programed cell death accounts for the atrophy of the portal blood-deprived liver lobes after PBL, by activation of both the mitochondrial and death receptormediated pathways. They further suggest that homeostatic mechanisms are activated in order to try and reduce the loss of liver mass induced by liver atrophy of the ligated lobes, when compensatory hyperplasia of the nonligated lobes is inhibited by retrorsine.

\section{Acknowledgements}

This work was in part supported by grants from Astra Zeneca, Belgium, from Glaxo-Smithkline, Belgium and a grant (3-4598) from FRSM, Belgium.

\section{References}

1 Rous P, Larimore L. Relation of the portal blood to liver maintenance: a demonstration of liver atrophy conditional on compensation. J Exp Med 1920;31:609-632.

2 Laurent S, Otsuka M, De Saeger C, et al. Expression of presumed specific early and late factors associated with liver regeneration in different rat surgical models. Lab Invest 2001;81:1299-1307.

3 Lambotte L, Li B, Leclercq I, et al. The compensatory hyperplasia (liver regeneration) following ligation of a portal branch is initiated before the atrophy of the deprived lobes. J Hepatol 2000;32:940-945.

4 Starkel P, Horsmans Y, Sempoux C, et al. After portal branch ligation in rat, nuclear factor kappaB, interleukin-6, signal transducers and activators of transcription 3, c-fos, c-myc, and c-jun are similarly induced in the ligated and nonligated lobes. Hepatology 1999;29:1463-1470.

5 Kerr JF. Shrinkage necrosis: a distinct mode of cellular death. J Pathol 1971;105:13-20.

6 Kerr JF, Wyllie AH, Currie AR. Apoptosis: a basic biological phenomenon with wide-ranging implications in tissue kinetics. Br J Cancer 1972;26:239-257.

7 Mizuno S, Nimura Y, Suzuki H, et al. Portal vein branch occlusion induces cell proliferation of cholestatic rat liver. J Surg Res 1996;60:249-257.

8 Harada H, Imamura H, Miyagawa S, et al. Fate of the human liver after hemihepatic portal vein embolization: cell kinetic and morphometric study. Hepatology 1997;26:1162-1170.

9 Tsugane K, Tamiya-Koizumi K, Nagino $\mathrm{M}$, et al. A possible role of nuclear ceramide and sphingosine in hepatocyte apoptosis in rat liver. J Hepatol 1999;31: 8-17.

10 Labat-Moleur F, Guillermet C, Lorimier P, et al. TUNEL apoptotic cell detection in tissue sections: critical evaluation and improvement critical evaluation and improvement. J Histochem Cytochem 1998;46: 327-334.

11 Rust C, Gores GJ. Apoptosis and liver disease. Am J Med 2000;108:567-574

12 Xie Q, Khaoustov VI, Chung CC, et al. Effect of tauroursodeoxycholic acid on endoplasmic reticulum stress-induced caspase-12 activation. Hepatology 2002; 36:592-601.

13 Picard C, Lambotte L, Starkel P, et al. Retrorsine: a kinetic study of its influence on rat liver regeneration in the portal branch ligation model. J Hepatol 2003; 39:99-105.

14 Gordon GJ, Coleman WB, Hixson DC, et al. Liver regeneration in rats with retrorsine-induced hepatocellular injury proceeds through a novel cellular response. Am J Pathol 2000;156:607-619.

15 Laconi E, Oren R, Mukhopadhyay DK, et al. Long-term, near-total liver replacement by transplantation of isolated hepatocytes in rats treated with retrorsine. Am J Pathol 1998;153:319-329.

16 Dabeva MD, Petkov PM, Sandhu J, et al. Proliferation and differentiation of fetal liver epithelial progenitor 
cells after transplantation into adult rat liver. Am J Pathol 2000;156:2017-2031.

17 Takeuchi E, Nimura Y, Mizuno S, et al. Ligation of portal vein branch induces DNA polymerases alpha, delta, and epsilon in nonligated lobes. J Surg Res 1996;65:15-24.

18 Thompson CB. Apoptosis in the pathogenesis and treatment of disease. Science 1995;267:1456-1462.

19 Hockenbery D. Defining apoptosis. Am J Pathol 1995;146:16-19.

20 Evan G, Littlewood T. A matter of life and cell death. Science 1998;281:1317-1322.

21 Cain K, Freathy C. Liver toxicity and apoptosis: role of TGF-beta1, cytochrome $c$ and the apoptosome. Toxicol Lett 2001;120:307-315.
22 Adams JM, Cory S. The Bcl-2 protein family: arbiters of cell survival. Science 1998;281: 1322-1326.

23 Morishima N, Nakanishi K, Takenouchi H, et al. An endoplasmic reticulum stress-specific caspase cascade in apoptosis. Cytochrome $C$-independent activation of caspase-9 by caspase-12. J Biol Chem 2002;277: 34287-34294.

24 Ashkenazi A, Dixit VM. Death receptors: signaling and modulation. Science 1998;281:1305-1308.

25 Faubion WA, Gores GJ. Death receptors in liver biology and pathobiology. Hepatology 1999;29:1-4.

26 Fan G, Kren BT, Steer CJ. Regulation of apoptosisassociated genes in the regenerating liver. Semin Liver Dis 1998;18:123-140. 